\title{
Efektivitas Bioremedian dan Konsorsia Mikroba Penyubur terhadap Produksi dan Kandungan Timbal Gabah di Karanganyar
}

\author{
Effectiveness of Bioremedian and Microbial Consortium Fertilizer to the Yeild and Lead \\ Content of Grain in Karanganyar
}

\author{
Muslikhatun Mutmainnah $^{1)}$, Supriyadi ${ }^{2)}$, Edi Purwanto ${ }^{2)}$, Bambang Sukmadi ${ }^{3)}$
}

\section{ABSTRACT}

Food need in Indonesia always increases while its production tends to decrease. One of factors causing it is contaminants in agricultural environment including lead $(\mathrm{Pb})$. This research aimed to study the effectiveness of bioremediation and microbial consortia fertilizers in increasing rice production and decreasing lead contamination in grain. The research started in August 2013 to February 2014 in village Waru and Kebak, Kebakkramat, Karanganyar, using Nested Factorial Treatment Design and Complete Randomized Block Design with two factors those are bioremediation variety and combination microbial fertilizers with chemical fertilizers. Statistical analysis used F-test, Kruskal Wallis,Tukey 5\%, Mood Median, correlation test and regression. Research result showed best production was achieved at V2P1 (Pepe + Azolla 0,183 ton ha ${ }^{-1}$, microbial fertilizer 0,56 ton ha $^{-1}$ and chemical fertilizers $50 \%$ of farmer standard), that is highest result is achieved at total number of tillers $(35,64)$, number of productive tillers $(25,72)$, Dry Grain $\left(11\right.$ ton ha $\left.{ }^{-1}\right)$ and Dry Milled Grain $\left(8,7\right.$ ton $\left.\mathrm{ha}^{-1}\right)$. Azolla microphylla, microbial fertilizer and chemical fertilizers $50 \%$ of farmer standard treat was effective to reduce heavy metal residues because lead residues were not found on the grain ( $0 \mathrm{ppm})$.

Keywords : bioremediation, lead, rice

\section{PENDAHULUAN}

Kebutuhan pangan di Indonesia semakin meningkat seiring dengan meningkatnya laju pertumbuhan penduduk, akan tetapi produksi beras di Indonesia cenderung mengalami penurunan. Berdasarkan data BPS (2013), di Jawa Tengah saja dalam dua tahun terakhir produktivitas padi mengalami penurunan, yaitu pada tahun 2012 produktivitas mencapai $57,70 \mathrm{ku} \mathrm{ha}^{-1}$ dan pada 2013 mengalami penurunan menjadi $56,04 \mathrm{ku} \mathrm{ha}^{-1}$. Oleh karena itu produksi beras harus ditingkatkan agar dapat menjaga ketahanan pangan di Indonesia. Beberapa faktor yang menyebabkan menurunnya produksi beras adalah alih fungsi lahan pertanian untuk keperluan non pertanian, rendahnya kualitas benih yang digunakan, teknik budidaya pertanian yang kurang tepat (Anggraini 2013), serta adanya bahan pencemar di lingkungan pertanian yang mengakibatkan menurunnya kesuburan tanah dan menghambat pertumbuhan tanaman (Dewi dan Hindersah 2009). Bahan pencemar pada lahan pertanian dapat berasal dari kegiatan industri maupun kegiatan pertanian itu sendiri yaitu penggunaan bahan agrokimia yang kurang terkendali (Kurnia et al. 2004, Malidareh et al. 2014).

Logam berat sering ditemukan pada lahan pertanian seperti chromium, arsen, cadmium serta

1) Undergraduate Student of Study Program of Agrotechnology, Faculty of Agriculture University of Sebelas Maret (UNS) in Surakarta

2) Lecturer of Study Program of Agrotechnology, Faculty of Agriculture University of Sebelas Maret (UNS) in Surakarta

3) Researcher Staff of Deputy for Agroindustry and Biotechnology, Agency for the Assessement and Application of Technology

Contact Author: priyadi_hpt@yahoo.co.id timbal (Zhou et al. 2014). Timbal mampu diakumulasi oleh daun, batang, akar maupun umbi tanaman. Konsentrasi timbal yang tinggi dapat mengakibatkan pengaruh toksik pada fotosintesis dan pertumbuhan tanaman. Akumulasi timbal berlebihan pada tubuh dapat membahayakan kesehatan manusia (Widianingrum et al. 2007).

Kegiatan industri di Kabupaten Karanganyar pada umumnya terpusat di Kecamatan Jaten dan Kebakkramat (Triwahyudi dan Hartiwiningsih 2004). Wilayah tersebut dilalui aliran sungai yang ada dalam lingkup DAS Bengawan Solo (Dinas Lingkungan Hidup Kabupaten Karanganyar 2006). Air sungai yang tercemar oleh limbah industri digunakan sebagai sumber irigasi sehingga dikhawatirkan akan menyebabkan penurunan kualitas tanah sawah serta meracuni tanaman budidaya (Gautam et al. 2012). Kandungan pencemar dalam tanah dapat menurunkan produktivitas lahan sawah yang akhirnya akan berdampak pada berkurangnya produksi gabah total (Suganda et al. 2002).

Upaya perbaikan lahan tercemar dapat dilakukan dengan teknik remediasi (Walpola dan Yoon 2013), akan tetapi teknik remediasi konvensional seringkali sangat mahal dan dapat merusak kualitas lahan (Ward dan Singh 2004). Untuk itu perlu dilakukan upaya perbaikan kualitas lahan pertanian yang lebih murah dan ramah lingkungan yaitu dengan teknologi bioremediasi dengan memanfaatkan mikroorganisme untuk mendegradasi polutan menjadi kurang berbahaya atau tidak berbahaya (Roxana 2011), serta dapat pula dilakukan dengan fitoremediasi (Marchiol dan Fellet 2011). Kombinasi pupuk anorganik dengan pupuk hayati menjadi strategi efektif untuk meminimalkan penggunaan pupuk anorganik dan meningkatkan produktivitas padi (Ali et al. 2007). Oleh karena itu, dalam penelitian ini akan dilakukan pengujian terhadap efektifitas Azolla microphylla,

Efektivitas Bioremedian dan Konsorsia Mikrob Penyubur terhadap Produksi ..............

Muslikhatun Mutmainnah, Supriyadi, Edi Purwanto, Bambang Sukmadi 
mikrob bioremedian dan konsorsia mikrob penyubur sebagai pupuk hayati dengan pupuk anorganik dalam meningkatkan kualitas dan hasil produksi padi serta penurunan timbal pada gabah.

\section{METODE PENELITIAN}

Penelitian dilaksanakan pada bulan Agustus 2013 sampai Februari 2014 di Desa Waru dan Desa Kebak, Kecamatan Kebakkramat, Kabupaten Karanganyar.

Rancangan percobaan yang digunakan adalah metode eksperimen dengan rancangan perlakuan faktorial tersarang (Nested Design) dan rancangan lingkungan RAKL (Rancangan Acak Kelompok Lengkap) dengan 2 faktor yaitu: Varietas (Ciherang dan Pepe), dan kombinasi pupuk P1 (Azolla microphylla 0,183 ton $\mathrm{ha}^{-1}$, mikrob penyubur 0,56 ton $\mathrm{ha}^{-1}$ dan pupuk kimia $50 \%$ standar petani), P2 (mikrob remedian 102,9 liter ha ${ }^{-1}$, mikrob penyubur 0,56 ton ha $^{-1}$ dan pupuk kimia $50 \%$ standar petani), P3 (Azolla microphylla, mikrob penyubur, mikrob remedian dan pupuk kimia 50\% standar petani) dan P4 (pupuk kimia $50 \%$ standar petani)

Pengacakan dilakukan pada dua lokasi. Varietas Pepe diacak di Desa Waru dan varietas Ciherang di Desa Kebak. Ukuran petakan perlakuan kurang lebih $291 \mathrm{~m}^{2}$ dan ditempatkan pada 3 blok, sehingga total luas lahan percobaan di masing-masing desa adalah sekitar $3500 \mathrm{~m}^{2}$. Pelaksanaan Penelitian meliputi persiapan lahan, pengambilan sampel tanah awal, penanaman dan aplikasi mikrob penyubur, mikrob remedian dan sebar Azolla microphylla dan perlakuan lanjutan (30 HST), pemeliharaan tanaman serta pemanenan.

Variabel pengamatan meliputi, kondisi tanah awal, tinggi tanaman, jumlah anakan total dan produktif, berat brangkasan segar dan kering, berat 1000 biji, gabah kering panen dan giling serta kandungan timbal dalam gabah. Data dianalisis dengan uji $F 5 \%$ jika sebaran data normal, apabila terdapat beda nyata dilanjutkan dengan menggunakan uji Tukey 5\%, kemudian jika data tidak normal analisis dilakukan dengan uji non Parametrik Kruskall-Wallis dan apabila terdapat beda nyata dilanjutkan dengan uji
Mood'Median taraf 5\%. Untuk mengetahui hasil terbaik digunakan uji korelasi dan regresi

\section{HASIL DAN PEMBAHASAN \\ Kondisi Umum Lokasi Penelitian}

Jenis tanah di lokasi penelitian yaitu Vertisol. Tanah vertisol merupakan tanah yang mempunyai sifat khusus, yaitu sifat vertik, karena adanya mineral liat tipe 2:1 (Munir 1996). Berdasarkan tabel tersebut diketahui nilai $\mathrm{pH}$ rata-rata di lokasi penelitian tergolong netral $(6,85)$ dan Kapasitas Tukar Kation (KTK) yang tinggi (22,4 $\mathrm{me} \%)$, sejalan dengan Nursyamsi (2005) dan Prasetyo (2007) yang menyatakan bahwa tanah vertisol memiliki $\mathrm{pH}$ agak masam hingga netral serta KTK yang tinggi karena tingginya kandungan klei. Kemudian untuk kandungan bahan organik tanah tergolong rendah $(1,60)$, yang dapat disebabkan karena praktek budidaya petani (Pramono 2004). Populasi mikrobia pada tanah di lokasi penelitian adalah 7,82 log CFU (Coloni Forming Unit)/gram tanah. Menurut Schnitzer (1997), bahan organik merupakan sumber nutrisi bagi mikroorganisme dalam tanah. Kadar kesuburan lainnya yakni $\mathrm{P}$ dan $\mathrm{K}$ menunjukkan nilai pengharkatan yang tinggi dengan kadar $P$ sebesar 25,77 ppm dan kadar K tertukar sebesar 0,73 mg 100 $\mathrm{g}^{-1}$.

\section{Komponen Pertumbuhan}

Faktor genetik dan lingkungan mempengaruhi fase vegetatif tanaman dan nantinya akan berpengaruh terhadap fase generatif (Anggraini 2013). Aplikasi Azolla microphylla mampu meningkatkan ketersediaan $\mathrm{N}$ yang diperlukan untuk menunjang fase vegetatif tanaman (Bocchi dan Malgioglio 2010), selain itu, menurut Mihir dan Ramesh (2013), penggunaan mikrobia yang dikombinasikan dengan pupuk kimia mampu meningkatkan asimilasi nitrat pada tanah sawah. Berdasarkan analisis statistik diketahui bahwa varietas berpengaruh pada komponen pertumbuhan kecuali berat brangkasan kering, sedangkan pupuk hanya berpengaruh pada jumlah anakan total (Tabel 1).

Tabel 1. Pengaruh varietas dan pupuk terhadap komponen pertumbuhan

\begin{tabular}{lccccc}
\hline Perlakuan & $\begin{array}{c}\text { Tinggi } \\
\text { tanaman } \\
(\mathrm{cm})^{\star}\end{array}$ & $\begin{array}{c}\text { Jumlah Anakan } \\
\text { Total } \\
\text { (batang/rumpun**) }\end{array}$ & $\begin{array}{c}\text { Jumlah Anakan Produktif } \\
\text { (batang/rumpun**) }\end{array}$ & $\begin{array}{c}\text { Berat Brangkasan } \\
\text { Segar (gram) }\end{array}$ & $\begin{array}{c}\text { Berat Brangkasan } \\
\text { Kering (gram) }\end{array}$ \\
\hline Varietas & & & & & \\
V1 & $92,10^{\mathrm{a}}$ & $26,4^{\mathrm{a}}$ & $18,90^{\mathrm{a}}$ & \\
V2 & $95,90^{\mathrm{b}}$ & $32,4^{\mathrm{b}}$ & $24,92^{\mathrm{b}}$ & $316,3^{\mathrm{a}}$ & $5,36^{\mathrm{a}}$ \\
Kombinasi & & & & $5,36^{\mathrm{b}}$ \\
Pupuk & & & & \\
P1 & $92,10^{\mathrm{a}}$ & $31,00^{\mathrm{b}}$ & $22,50^{\mathrm{a}}$ & $23,37^{\mathrm{a}}$ & $48,80^{\mathrm{a}}$ \\
P2 & $95,50^{\mathrm{ab}}$ & $30,80^{\mathrm{b}}$ & $22,73^{\mathrm{a}}$ & $24,35^{\mathrm{a}}$ & $52,79^{\mathrm{a}}$ \\
P3 & $92,55^{\mathrm{a}}$ & $29,40^{\mathrm{ab}}$ & $21,17^{\mathrm{a}}$ & $23,98^{\mathrm{a}}$ & $55,50^{\mathrm{a}}$ \\
P4 & $95,80^{\mathrm{ab}}$ & $26,40^{\mathrm{a}}$ & $21,23^{\mathrm{a}}$ & $23,17^{\mathrm{a}}$ & $50,34^{\mathrm{a}}$ \\
\hline
\end{tabular}

Keterangan: Angka yang diikuti huruf yang sama pada kolom yang sama menunjukkan beda tidak nyata pada, ${ }^{*}$ uji Non Parametrik (Mood' Median) taraf $5 \%,{ }^{* *}$ ) uji Tukey taraf $5 \%$.

Hasil uji korelasi menunjukkan varietas memiliki hubungan yang erat dengan tinggi tanaman, jumlah anakan, jumlah anakan produktif dan berat brangkasan segar, untuk itu dilakukan analisis regresi untuk mengetahui bentuk hubungan varietas, pupuk terhadap tinggi tanaman, jumlah anakan, jumlah 
anakan produktif dan berat brangkasan kering. Hasil estimasi regresi menunjukkan pupuk merupakan variabel pemoderasi dari varietas karena dapat meningkatkan nilai R-sq (adj) (pengaruh perlakuan). Variabel moderasi merupakan variabel bebas yang memperkuat hubungan antara variabel bebas lain terhadap variabel tergantungnya (Preacher et al. 2007). Berdasarkan Gambar 1 dapat diketahui tinggi
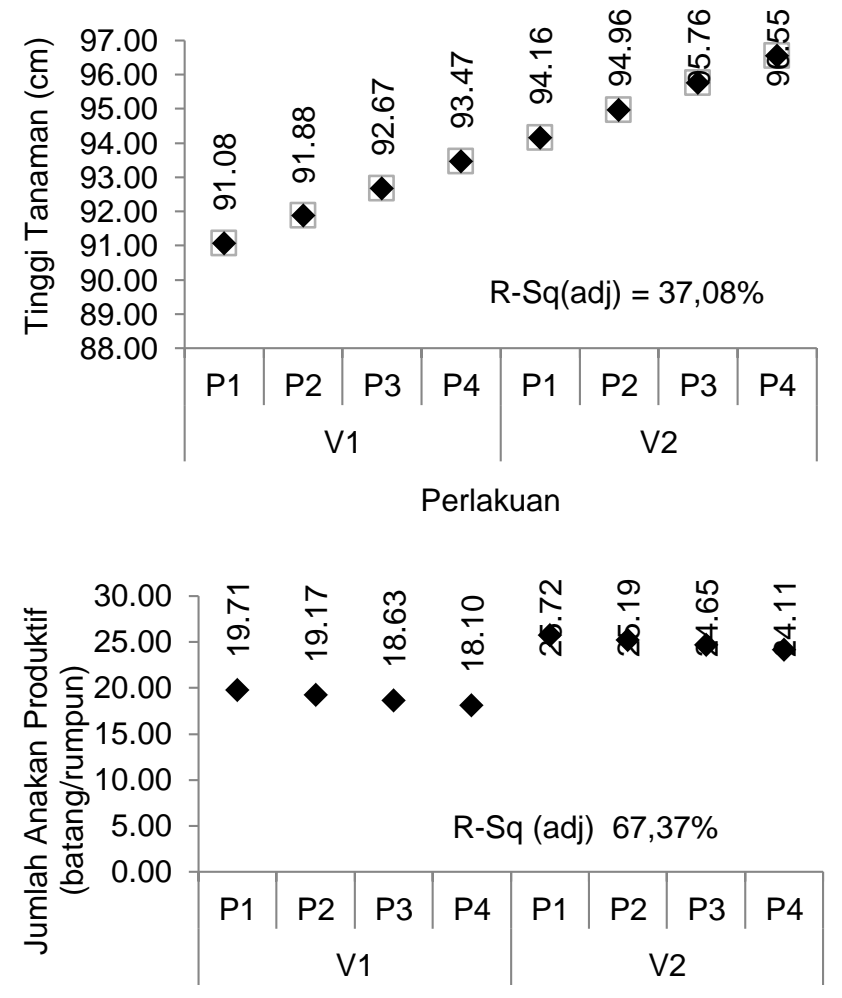

Perlakuan tanaman tertinggi dicapai pada V2P4. Jumlah anakan total dan produktif terbanyak pada V2P1. Akan tetapi hasil berat brangkasan menunjukkan pupuk bukan variabel pemoderasi dari varietas karena dengan adanya pupuk nilai R-sq menurun. Hasil berat brangkasan terbesar dicapai pada V2 (Varietas Pepe).

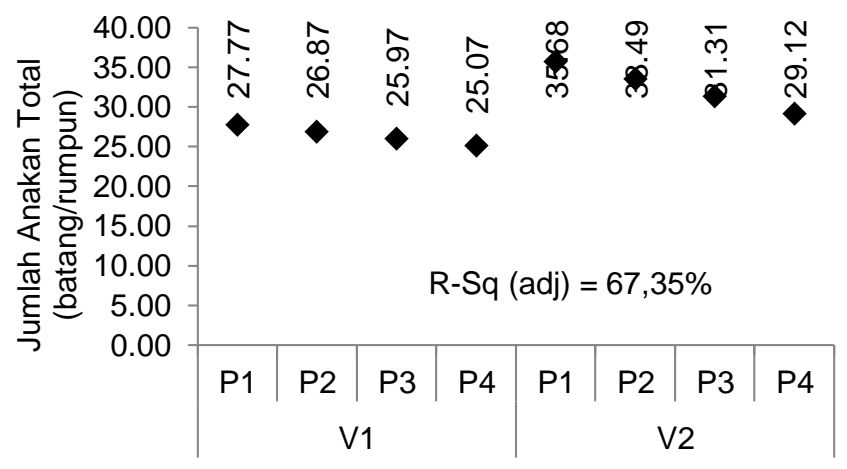

Perlakuan

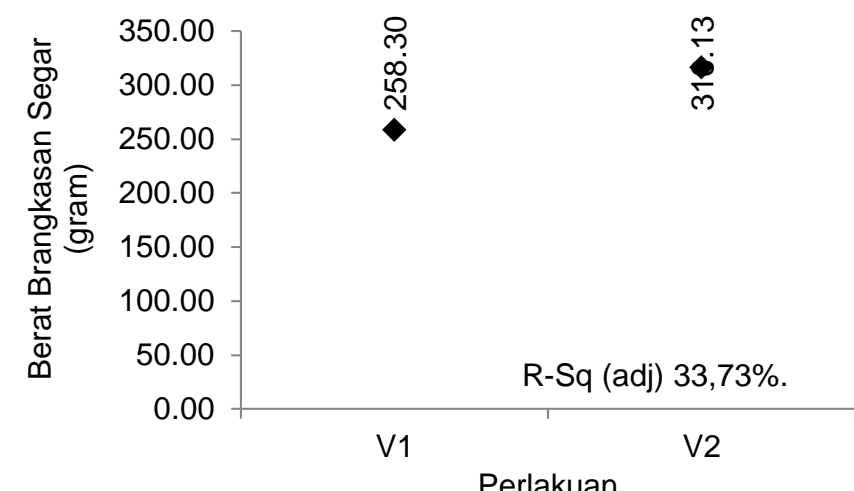

Perlakuan

Gambar 1. Hasil estimasi regresi hubungan varietas dan pupuk terhadap tinggi tanaman, jumlah anakan total, jumlah anakan produktif dan berat brangkasan segar

\section{Komponen Hasil}

Keberadaan input yang berupa pupuk hayati (konsorsia mikrobia) dapat meningkatkan produktivitas pertanian (Saraswati et al. 2008). Hasil analisis ragam menunjukkan varietas berpengaruh terhadap berat gabah kering panen (GKP), gabah kering giling (GKG) dan berat 1000 biji sedangkan perlakuan pupuk tidak berpengaruh terhadap hasil padi. Berdasarkan uji Tukey 5\%, V2 memberikan hasil GKP dan GKG lebih besar dari V1 kecuali pada berat 1000 biji. Perlakuan P4 menunjukkan hasil terendah dibanding perlakuan lain, tapi tidak berbeda nyata menurut uji Tukey 5\% (Tabel 2).

Tabel 2. Pengaruh varietas dan pupuk terhadap komponen pertumbuhan

\begin{tabular}{llll}
\hline Perlakuan & Gabah Kering Panen (gram) & Gabah Kering Giling (gram) & Berat 1000 Biji (gram) \\
\hline Varietas & & \\
V1 & $45,11^{\mathrm{a}}$ & $41,51^{\mathrm{a}}$ & $24,17^{\mathrm{b}}$ \\
V2 & $65,76^{\mathrm{b}}$ & $52,83^{\mathrm{b}}$ & $23,27^{\mathrm{a}}$ \\
Kombinasi Pupuk & & & \\
P1 & $57,30^{\mathrm{a}}$ & $49,71^{\mathrm{a}}$ & $23,37^{\mathrm{a}}$ \\
P2 & $56,67^{\mathrm{a}}$ & $48,24^{\mathrm{a}}$ & $24,35^{\mathrm{a}}$ \\
P3 & $56,20^{\mathrm{a}}$ & $47,67^{\mathrm{a}}$ & $23,98^{\mathrm{a}}$ \\
P4 & $51,57^{\mathrm{a}}$ & $43,06^{\mathrm{a}}$ & $23,17^{\mathrm{a}}$ \\
\hline
\end{tabular}

Keterangan: Angka yang diikuti huruf yang sama menunjukkan beda tidak nyata pada uji Tukey taraf $5 \%$. 
Hasil uji korelasi menunjukkan varietas memiliki hubungan yang erat dengan GKP dan GKG, untuk itu dilakukan analisis regresi untuk mengetahui bentuk hubungan varietas, pupuk terhadap GKP dan GKG. Hasil estimasi regresi menunjukkan pupuk merupakan variabel pemoderasi dari varietas karena dapat meningkatkan nilai R-sq (adj). Berdasarkan Gambar 2 dapat diketahui hasil GKP dan GKG terbaik menurut estimasi regresi yaitu pada V2P1 sebesar 68,41 gram/rumpun atau 11 ton ha $^{-1}$ GKP dan 53,83 gram/rumpun atau 8,7 ton ha ${ }^{-1}$ GKG.
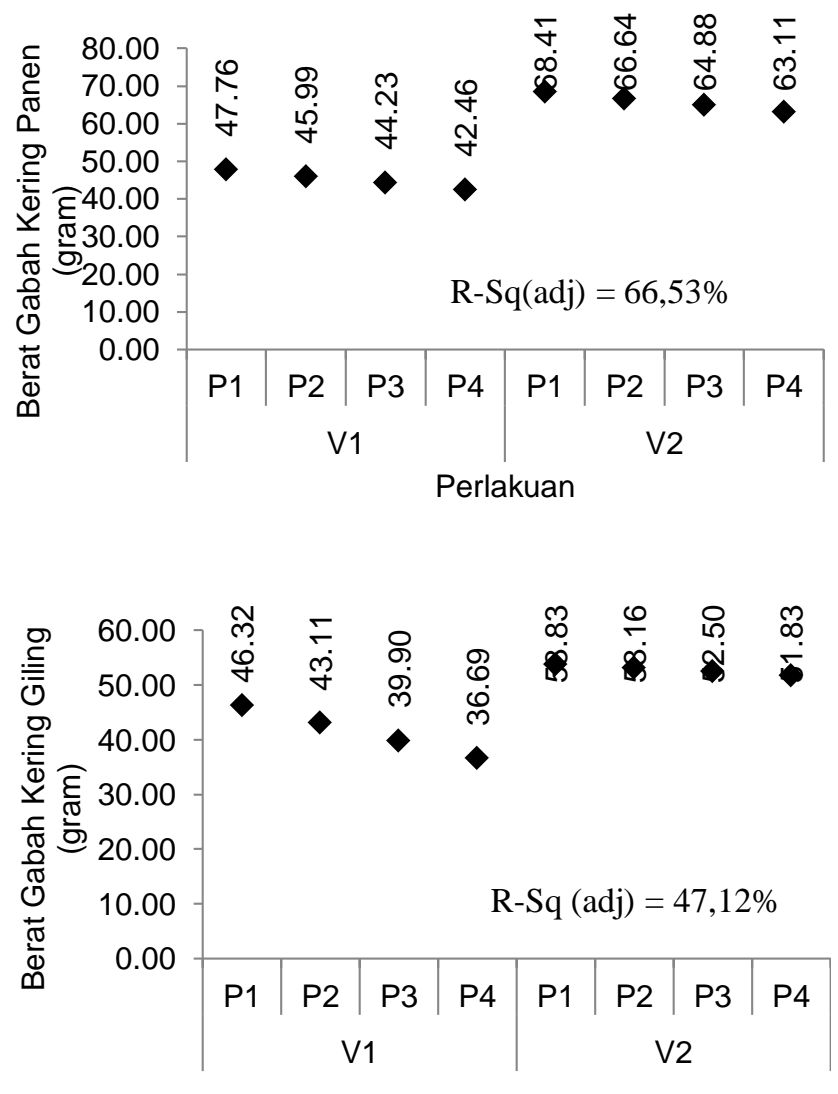

Perlakuan

Gambar 2. Hasil estimasi regresi hubungan varietas dan pupuk terhadap GKP dan GKG

\section{Kandungan Timbal $(\mathrm{Pb})$ dalam Gabah}

Tabel 3 menunjukkan hasil analisis kandungan logam berat timbal $(\mathrm{Pb})$ pada gabah. Kandungan terbesar timbal pada gabah ditemukan pada V1P4 (Varietas Ciherang + Azolla microphylla, mikrob penyubur dan pupuk kimia $50 \%$ standar petani) yaitu 2,5 ppm. Hasil ini menunjukkan bahwa kandungan timbal pada bulir padi masih ada yang melebihi batas maksimum residu. Menurut SNI (2009) batas maksimum residu pada padi maupun olahan turunannya adalah $0,3 \mathrm{ppm}$. Berdasarkan gambar 3 diketahui bahwa perlakuan terbaik ditunjukkan pada P1 (A. microphylla $\left(0,183\right.$ ton ha $\left.{ }^{-1}\right)$, mikroba penyubur $\left(0,56\right.$ ton ha $\left.{ }^{-1}\right)$ dan pupuk kimia $50 \%$ standar petani (150 kg ha ${ }^{-1}$ ) karena tidak ditemukan residu timbal baik pada V1 maupun V2.
Tabel 3. Kandungan timbal $(\mathrm{Pb})$ dalam gabah

\begin{tabular}{ccc}
\hline \multicolumn{2}{c}{ Perlakuan } & $\begin{array}{c}\text { Kandungan Timbal pada } \\
\text { Gabah (ppm) }\end{array}$ \\
\hline $\mathrm{V} 1$ & P1 & 0 \\
& P2 & 1 \\
& P3 & 1,5 \\
V2 & P4 & 2,5 \\
& P1 & 0 \\
& P2 & 0,5 \\
& P3 & 0 \\
& P4 & 0 \\
\hline
\end{tabular}

A. microphylla memiliki kemampuan untuk menurunkan cemaran logam $\mathrm{Pb}$ serta bersifat toleran terhadap konsentrasi timbal nitrat yang tinggi (20-50 ppm) sehingga sering digunakan sebagai agen fitoremedian (Eyini et al. 2000). Pupuk hayati dengan menggunakan mikrobia penyubur telah banyak digunakan untuk meningkatkan kesuburan tanah dan menurunkan cemaran logam (Mihir dan Ramesh 2013), Tanaman dapat menyerap timbal pada saat kondisi kesuburan dan kandungan bahan organik tanah rendah (Verloo 1993). Berdasarkan analisis tanah awal menunjukkan kandungan bahan organik tanah yang rendah di lokasi penelitian yaitu 1,60 ppm sehingga memungkinkan timbal dapat terserap oleh tanaman. Lokasi penelitian dilalui aliran sungai yang ada dalam lingkup DAS Bengawan Solo (Dinas Lingkungan Hidup Kabupaten Karanganyar 2006). Batas maksimum residu untuk mengairi lahan pertanian yaitu 2 ppm, akan tetapi menurut (BLH Karanganyar 2013) kandungan $\mathrm{Pb}$ dalam air baik hulu maupun hilir sungai irigasi masih dibawah ambang batas $(<0,005)$, sehingga kemungkinan timbal yang terserap oleh tanaman lebih dipengaruhi oleh praktek budidaya petani.

Kegiatan pertanian di lokasi penelitian cenderung menggunakan pupuk anorganik yang berlebihan, sehingga kesuburan tanah menjadi rendah dan menurunkan mikroorganisme tanah menjadi berkurang. Hal inilah yang diduga mengakibatkan aplikasi pupuk hayati seperti mikrob penyubur, mikrob remedian dan $A$. microphylla belum bisa berkembang secara optimal di lahan mengingat aplikasi ini baru diujikan pertama kali di lahan tersebut. Menurut Saraswati (2008), pupuk hayati terdiri dari makhluk hidup yang memerlukan penanganan serta pemeliharaan khusus agar tetap hidup dan berkembang dalam tanah setelah inokulasi.

Berdasarkan analisis kandungan timbal gabah dalam tanah, kandungan timbal berada pada kisaran 9-11 ppm. Menurut Alloway (1993), batas maksimum residu dalam tanah yaitu 100-400 ppm, sehingga tanah di dua lokasi memiliki kandungan residu timbal yang masih dibawah ambang batas dan belum mengganggu pertumbuhan tanaman. Menurut (Widaningrum et al. 2007), konsentrasi timbal yang akan mengakibatkan pengaruh toksik dan mengganggu proses fotosintesis yaitu 100-1000 ppm. Meski belum menganggu pertumbuhan tanaman, residu timbal dapat diserap oleh akar tanaman sehingga dapat mengakibatkan akumulasi timbal dalam jaringan tanaman dan jika dikonsumsi oleh 
manusia terus menerus tentunya akan berdampak buruk pada kesehatan.

\section{KESIMPULAN DAN SARAN}

\section{Kesimpulan}

Berdasarkan hasil penelitian dapat diambil beberapa kesimpulan yaitu:

1. Bioremedian dan konsorsia mikrob penyubur tidak efektif mempengaruhi pertumbuhan dan produksi tanaman karena hanya berpengaruh nyata pada jumlah anakan total yang diperoleh

2. Hasil produksi terbaik dicapai pada V2P1 (Varietas Pepe + Azolla microphylla 0,183 ton ha ${ }^{-1}$, mikrob penyubur 0,56 ton ha ${ }^{-1}$ dan pupuk kimia $50 \%$ standar petani) karena didapatkan hasil tertinggi pada jumlah anakan total $(35,64)$, jumlah anakan produktif $(25,72)$, GKP (11 ton ha $\left.{ }^{-1}\right)$ dan GKG $(8,7$ ton $\left.\mathrm{ha}^{-1}\right)$.

3. Azolla microphylla, mikrob penyubur dan pupuk kimia $50 \%$ standar petani efektif menurunkan residu logam berat karena tidak ditemukan residu timbal pada gabah di kedua lokasi.

\section{Saran}

Penelitian lanjutan mengenai kombinasi bioremedian dan konsorsia mikrob penyubur yang dikombinasikan dengan pupuk kimia dengan dosis yang berbeda perlu dilakukan untuk mengetahui lebih lanjut efektivitas kombinasi pupuk hayati dan pupuk kimia dalam meningkatkan produksi padi dan menurukan cemaran logam berat pada tanah sawah serta mengurangi ketergantungan petani terhadap penggunaan pupuk kimia.

\section{DAFTAR PUSTAKA}

Ali MA, Sattar MA, Islam MN, Inubushi K. 2014. Integrated effects of organic, inorganic and biological amendments on methane emission, soil quality and rice productivity in irrigated paddy ecosystem of Bangladesh: field study of two consecutive rice growing seasons. J Plant Soil 378 (1-2): 239- 252.

Alloway BJ. 1995. Heavy metals in soils. $2^{\text {nd }}$. Blackie Glasgow, and London Halstead Press. John Wiley and Sons Inc.

Anggraini F, Suryanto A, Aini N. 2013. Sistem tanam dan umur bibit pada tanaman padi sawah (Oryza sativa L.) varietas inpari. J Prod Tan 8(2): 50-60.

BPS [Badan Pusat Statistik]. 2013. Produksi tanaman padi seluruh provinsi. http://bps.tnmnpgn.go.id. Diakses tanggal 9 Februari 2014.

Bocchi S dan Malgioglio A. 2010. Azolla-anabaena as a bioertilizer for rice paddy fields in the po valley, a temperate rice area in northern italy. International J Agron. 2010. 1-5.

Dewi T, Hindersah R. 2009. Konsentrasi kadmium dan timbal di tanaman mendong yang ditanam di tanah sawah dengan aplikasi azotobacter dan arang aktif. J Agric 20(3): 185-190.

Dinas Lingkungan Hidup Kabupaten Karanganyar. 2006. Karanganyar (ID): Laporan status lingkungan hidup daerah kabupaten Karanganyar Tahun 2006.

Eyini WM, Devi NA, Pothiraj C, Jayakumar M, Kil BS. 2000. Differential responses of Azolla microphylla kaulf and Azolla filiculoides Lam. to lead nitrate. J Plant Biol 43(1): 18-21.

Gautam RK, Chattopadhyaya, Sharma SK. 2012. Biosorption of heavy metals: recent trends and challenges. J Watewater Reuse Manag : 305-322.

Kurnia U, Suganda H, Saraswati R, Nurjaya. 2004. Teknologi pengendalian pencemaran lahan sawah. dalam tanah sawah dan teknologi pengelolaannya, halaman 249-283. Bogor (ID): Puslitbang Tanah dan Agroklimat. Badan Litbang Pertanian.

Marchiol L, Fellet G. 2011. Agronomy towards the green economy. optimization of metal phytoextraction. Italian J Agron 6(3): 30. http://agronomy.it/index.php/agro/article/view/ija.20 11.e30 [Accessed April 29, 2014].

Mihir RL, Ramesh SC. 2013. Effect of integrated use of chemical fertilizer and bioinoculents on growth, nitrate assimilation and yield of rice (Oryza sativa L.) Indian J Agr Res. 47(5): 419-424.

Nursyamsi D, Suprihati. 2005. Sifat-sifat kimia dan mineralogi tanah serta kaitannya dengan kebutuhan pupuk untuk padi (Oryza sativa), jagung (Zea mays), dan kedelai (Glycine max). Bul. Agron. 33(3): 40-47.

Pramono J. 2004. Kajian penggunaan bahan organik pada padi sawah. J Agros 6(11): 11-14.

Prasetyo BH. 2007. Perbedaan sifat-sifat tanah vertisol dari berbagai bahan induk. J IImu Pert 9 (1): 20-33. ISSN 1411- 0067.

Preacher KJ, Hayes AF. 2007. Assesing moderated mediation hypothesis, multivariated behavioral research. 42: 387-400.

Roxana AE 2011. An approach to bioremediation. J of Engineering Studies and Research. 17(4): 7-12.

Saraswati R, Sumarno. 2008. Pemanfaatan mikroba penyubur tanah sebagai komponen teknologi pertanian. J Iptek Tanaman Pangan 3(1).

SNI [Standar Nasional Indonesia]. 2009. Batas maksimum cemaran logam berat dalam pangan. SNI. 7387: 2009. Badan Standarisasi Nasional. ICS.67.220.20.

Suganda H, Setyorini D, Kusnandi H, Saripin I. 2002. Kelestarian lahan sawah evaluation of the pollution of liquid wastes textile. prosiding seminar nasional dan konversi lahan pertanian: 203-221.

Triwahyudi P, Hartiwiningsih. 2004. Kebijakan pengendalian pencemaran air akibat kegiatan industri di kabupaten Karanganyar. PPLH UNS. Surakarta. 
Verloo M. 1993. Chemical aspect of soil pollution. ITC-Gen Publications series. 4: 17-46.

Walpola BC, Yoon M. 2013. Agricultural methods for toxicity alleviation in metal contaminated soils: A Review. Korean J Soil Sci Fert. 46(2): 73-80.

Ward PO, Singh. 2004. Evaluation of current soil bioremediation technologies. Soil Biology 1: 187214.
Widaningrum Miskiyah, Suismono. 2007. Bahaya kontaminasi logam berat dalam sayuran dan alternatif pencegahan cemarannya. Bul Tek Pascapanen Pertanian, 3 (Balai Besar Penelitian dan Pengembangan Pascapanen Pertanian): 1627.

Zhou $\mathrm{H}$ et al. 2014. Effect of combined amendements on heavy metal accumulation in rice (Oryza sativa L) planted on contaminated paddy Soil. Ecotoxicology and Eviromental Savety 101: 226232. 